\title{
ANÁLISIS COMPARATIVO DE LA EDUCACIÓN DE LOS ESCRIBANOS, NOTARIOS Y ABOGADOS EN COLOMBIA
}

\author{
Álvaro Enrique Rengifo Donado \\ Universidad del Tolima
}

\begin{abstract}
Resumen
El propósito de este artículo es entender por qué el derecho notarial no logra su independencia total como disciplina del derecho, en Colombia, sino hasta 1970, utilizando el rastreo comparativo de la educación de los abogados, los escribanos y notarios, con el fin de comprender el peso específico de la actividad notarial en sociedades premodernas o modernas para la solución de los conflictos o para la regulación de los intereses privados, como función del Estado. A partir de esta comparación, podrá contrastarse si la práctica notarial era una alternativa de la praxis jurídica en justicia preventiva y cuándo aparece ella como solución frente al desgastado argumento del poder político como el ejercicio de la violencia legítima o como árbitro de los intereses ciudadanos, solamente cuando ya existe contención. De igual modo, este ensayo hace parte de una tesis doctoral denominada "La función social del notario en la sociedad postsecular", dentro del programa de doctorado de la Red de Universidades Públicas de Colombia, del que hace parte la Universidad del Tolima.
\end{abstract}

Palabras clave: Derecho notarial, escribanos, abogados, notarios. 


\title{
COMPARATIVE ANALYSIS OF THE EDUCATION OF SCRIBES, NOTARIES, AND LAWYERS IN COLOMBIA
}

\begin{abstract}
The purpose of this article is to understand why the notarial right did not obtain total independence as a law discipline in Colombia until 1970. The investigation is conducted using comparative tracking of the education of lawyers, scribes and notaries, in order to understand the specific weight of notarial activity in premodern or modern societies in conflict solution or the regulation of private interests, as a function of the state. A comparison is made between notarial practice as an alternative to legal practice in preventive justice and when it appears as a solution to the outdated argument of political power as the exercise of legitimate violence, or as an arbiter of citizens' interests after restraint. This paper is part of a doctoral thesis entitled "The social function of the notary in post-secular society," within the doctoral program of the Network of Public Universities of Colombia (Red De Universidades Públicas de Colombia), which is part of the Universidad de Tolima.
\end{abstract}

Keywords: Notarial right, scribes, lawyers, notaries.

\section{ANÁLISE COMPARATIVA DA EDUCAÇÃO DO TABELIÃO, NOTÁRIOS E ADVOGADOS, NA COLÔMBIA}

\begin{abstract}
Resumo
O objetivo deste artigo é entender por que a lei do tabelião não consegue sua independência total como uma disciplina de Direito, na Colômbia, até 1970, usando o rastreamento comparativo da educação de advogados, tabelião e notários, a fim de compreender o peso específico da atividade notarial em sociedades pré-modernas ou modernas para a solução de conflitos ou para a regulação de interesses privados, como função do Estado. A partir dessa comparação, pode ser contrastado se a prática notarial era uma prática jurídica alternativa na justiça preventiva e quando aparece como solução frente ao desgastado argumento do poder político e do exercício da violência legítima ou como árbitro dos interesses dos cidadãos aparece como uma solução, somente quando já houver confinamento. Da mesma forma, este ensaio é parte de uma tese de doutoramento intitulada "O papel social do notário na sociedade pós-secular" dentro do programa de doutorado da Rede de Universidades Públicas de Colômbia, que faz parte da Universidade de Tolima.
\end{abstract}

Palavras-chave: Notariado, tabelião, advogados, notários. 


\section{Introducción}

El propósito de este trabajo es entender por qué el derecho notarial no logra su independencia total como disciplina del derecho, en Colombia, sino hasta 1970. El procedimiento que se utilizará será el rastreo comparativo de la educación de los abogados y los escribanos y notarios, con el fin de comprender el peso específico de la actividad notarial en sociedades premodernas o modernas para la solución de los conflictos o para la regulación de los intereses privados, como función del Estado. A partir de esta comparación, podrá contrastarse si la práctica notarial era una alternativa de la praxis jurídica en justicia preventiva y cuándo aparece ella como solución frente al desgastado argumento del poder político como el ejercicio de la violencia legítima o como árbitro de los intereses ciudadanos, solamente cuando ya existe contención. De igual modo, este ensayo hace parte de una tesis doctoral denominada "La función social del notario en la sociedad postsecular", dentro del programa de doctorado de la Red de Universidades Públicas de Colombia, del que hace parte la Universidad del Tolima.

\section{Algo de historia}

En la Colonial la labor de escribano era uno de los denominados "oficios de pluma”. Por consiguiente, al menos, en las leyes, siempre se exigieron condiciones mínimas de escolaridad, habilidad jurídica y honorabilidad a quienes ejercían tal tarea. El nombrado debía ser español u oriundo del lugar donde debía actuar y no podía ser mestizo o mulato, ni ser encomendero; “...se requería la presentación de documentos que acreditaran un nacimiento legítimo y "pureza de sangre"1, discriminación que con el tiempo fue desdibujándose ${ }^{2}$; el acceso al cargo ocurría mediante examen practicado por la Audiencia o el Gobernador y se requería una práctica profesional no inferior a dos años. Ejercían un oficio "público e honrado e comunal para todos" y no podían dejar de realizar su cometido "por amor, ni por desamor, ni por miedo, ni por venganza de algún home ${ }^{3}$. En forma similar, en consonancia con los imaginarios culturales de la época, se pronuncia Jaime Jaramillo Uribe quien, al destacar las diferencias sociales por la "limpieza de sangre" habla de la división de oficios en nobles y plebeyos, reservándose para los limpios de sangre, los primeros quehaceres y para mestizos, indígenas y negros, los otros. Entre los oficios nobles estaban los de la burocracia "(...) aún en los más modestos niveles, como las escribanías de oficinas públicas, así como las profesiones de jurisprudencia y oficios eclesiásticos"4.

1. Manuel Cubides Romero, Derecho Notarial Colombiano (Bogotá: Universidad Externado de Colombia, 1978), 77.

2. Marco Palacios y Frank Safford, Historia de Colombia, país fragmentado, sociedad dividida (Bogotá: Ediciones Uniandes, 2002), 104.

3. Fuero Real, Título Octavo del Libro I, Ley 3a . Cubides Romero, "Derecho Notarial Colombiano", 77-562.

4. Jaime Jaramillo Uribe, Ensayos de Historia Social (México, D.F.: CESO, Ediciones Uniandes, ICANH, Alfaomega Colombiana S.A., 2001), 143. 
Los antecedentes históricos indican que no hubo relación directa entre aprendizaje formal y la adquisición del saber notarial por parte del escribano de la Colonia. Menciona Tamar Herzog en su obra "Mediación, archivos y ejercicio, los escribanos de Quito, Siglo XVII" lo siguiente: “(...) los futuros escribanos iniciaban sus carreras, generalmente, como escribientes o como oficiales menores o mayores de un oficio"5. Tenían a su disposición el archivo de la escribanía, para imitar o mejorar la redacción de documentos nuevos, utilizaban, igualmente, manuales prácticos con formularios y explicaciones o, en otros casos, adquirían su habilidad en otros oficios similares como procuradores, agentes del Real Fisco y protectoría general de los naturales.

“(...) La posibilidad de aprender la materia del escribano sin acudir a escuelas ni leer, necesariamente libros, no se cuestionó en la época estudiada. A pesar de ser un trabajo de carácter sustantivo, relacionado con un contenido legal y de alta responsabilidad e influencia, fue considerado como una técnica de tipo artesano más que como una ciencia elaborada, abstracta y de difícil aprendizaje (...) el saber notarial fue clasificado como un depósito de respuestas a problemas materiales concretos y como una fuente de reglas sensatas de aplicación de instrucciones consideradas de por sí como de fácil lectura y de comprensión”6.

En sentido similar se pronuncia la historiadora Kathryn Burns, apoyándose en Ángel Rama, quien destaca que los escribanos no estaban incluidos dentro de la categoría de letrados porque no habían cursado estudios formales ni conocían el latín. "... Ellos constituían una especie de sub-letrados... No obstante, conocían las fórmulas legales necesarias para producir un sujeto textual, el yo que nos habla por medio de los documentos..."7.

Una vez confirmado el nombramiento, el escribano se presentaba ante el cabildo, y prestaba el debido juramento, ante un Cristo “... y, mediante él, el escribano se comprometía a cumplir las siguientes obligaciones: que usaría "bien y fielmente" el oficio, guardando el servicio de Dios y del rey. Que escribiría lo que las partes otorgaren, "sin quitar la verdad ni añadir falsedad". Que guardaría secreto, en los casos que así requirieran. Que no haría contratos fraudulentos o usurarios. Que llevaría un "registro" de todas sus escrituras. Que prestaría sus servicios sin dilación y a todo el que se solicitare. Y que sería fiel y obediente a la ciudad".

5. Tamar Herzog, Mediación, archivos y ejercicio: Los escribanos de Quito (siglo XVII) (Frankfurt: Vittorio Klostermann Frankfurt am Main, 1996), 33.

6. Tamar Herzog, Mediación, archivos y ejercicio: Los escribanos de Quito (siglo XVII)", 34-35.

7. Kathryn Burns, "Dentro de la ciudad letrada: la producción de la escritura pública en el Perú colonial", Revista Histórica, Vol. 29, Núm. 1 (2005): 43-68, http://revistas.pucp.edu.pe/index.php/historica/ article/view/29/35 (25 de marzo de 2016). 
En cuanto a la educación de los escribanos, en los documentados textos sobre educación de los abogados de los profesores Goyes ${ }^{8}$, Uribe Ángel ${ }^{9}$, y Gaitán Bohórquez ${ }^{\mathbf{1 0}}$ no aparece ninguna mención expresa que permita colegir que hubiera algún currículo relativo a la educación de éstos. Con fundamento en la legislación de la época y los textos de historiadores de este periodo, podemos concluir que, así como en la Colonia, solamente era necesario que tuvieran destrezas en lectura, escritura y redacción de contratos y providencias judiciales ${ }^{\mathbf{1 1}}$, y experiencia deseable en despachos notariales, lo mismo ocurrió durante el siglo XIX, con algunas interesantes excepciones. En todo caso, a lo anterior, debe sumarse la circunstancia que la profesión del derecho no fue reglamentada sino en la segunda mitad del siglo XX y la exigencia del título de abogado, para notarios de primera categoría, lo fue hasta 1970.

Los cambios ocurridos en el régimen legal del notariado, en 1852, hicieron alusión a la organización misma del notariado, pero no así, a sus funciones básicas, salvo en lo relativo al registro civil de las personas, como mecanismo tendiente a la igualdad ciudadana, sin componentes religiosos y las pruebas judiciales. Su función orientadora o consultora fue centralizándose en las poblaciones pequeñas, pero no, de igual manera, en las ciudades, lugares en los cuales los abogados y litigantes calificados hacían presencia "académica". Al respecto, debemos reiterar que no se requería formación profesional para ser notario ni las facultades de derecho le daban alguna importancia a esta rama del derecho.

Debe destacarse que desde 1978 aparece documentada la asignatura de Derecho Notarial y Registral, como área de profundización, en la Universidad del Rosario, claustro del cual son egresados muchos de los notarios de fines del siglo XX y parte del XXI, en ciudades como Bogotá y ciudades capitales de departamento. En sentido muy semejante ocurre en la Universidad Externado de Colombia que inaugura la especialización en Derecho Notarial y Registral en 1993 y que ya tenía un área de profundización en el pensum de pregrado.

En cuanto a la forma de asumir la comprensión del derecho los notarios, es pertinente recordar que el neoclasicismo kelseniano que se introdujo a partir de los años 30, va a tener un vigoroso predominio en la forma como se interpretará el derecho colombiano en todos los ámbitos, incluido el notarial, durante todo lo que resta del siglo XX y lo que va corrido del siglo XXI. Dentro de este orden de ideas, la

8 Isabel Goyes Moreno, La enseñanza colonial del derecho en la vida Independiente, http://ceilat.udenar. edu.co/wp-content/uploads/2011/03/La-Ense\%C3\%B1anza-Colonial-del-Derecho-en-la-VidaIndependiente.pdf (15 de septiembre de 2015).

9. Jorge Tomás Uribe Ángel, Historia de la enseñanza en el Colegio Mayor del Rosario 1653-1767 (Bogotá: Centro Editorial Rosarista, 2003).

10. Julio Gaitán Bohorquez, Huestes de Estado, la formación universitaria de los juristas en los comienzos del Estado colombiano (Bogotá: Centro Editorial Universidad del Rosario, 2002).

11. Catherine LeGrand y Adriana Mercedes Corso, "Los archivos notariales como fuente histórica: Una visión desde la Zona Bananera del Magdalena", Anuario Colombiano de Historia Social y de la Cultura, No. 30 (2003): 159-208, http://www.bdigital.unal.edu.co/14282/1/3-8166-PB.pdf (25 de marzo de 2016). 
incorporación del neoclasicismo kelseniano al derecho colombiano, simplemente ha sido la continuación de un modelo de pensamiento liberal decimonónico que puede resumirse así: "La concepción normativa a partir de la cual el derecho se agota en la ley positiva, fue incorporada a nuestra tradición en el siglo XIX. En ese marco, el respeto del principio democrático de generalidad de la ley positiva adoptado por los benthamistas desde el siglo XIX garantizaba la seguridad jurídica y contribuyó al fortalecimiento del formalismo. Así, la tradición jurídica instaurada por este camino se concretó en una concepción formalista para la cual la coacción y la voluntad del poder político tenían un lugar fundamental como elementos que distinguen a la ciencia del Derecho, de otras expresiones normativas como la moral"12.

Dentro de este orden de ideas, "Los abogados encontraron en la propuesta de la Teoría Pura del Derecho la oportunidad de hacer una ciencia jurídica cuya función ya no fuera conciliar a las normas con determinados contenidos de justicia o moral sino legitimar relaciones hegemónicas y de jerarquía construidas y arbitradas por ellos mismos, partiendo de un concepto formal de validez y gracias a la creencia en la existencia de criterios neutrales para identificar y aplicar normas jurídicas" 13 . En relación con esta forma de asumir la práctica del derecho, no fueron ajenos los notarios, entre otras razones, por su función aún puramente instrumental, cercana al derecho probatorio o al derecho procesal y porque al no tener capacidad jurídica para "decir el derecho", característica que aún conserva, era más consecuente actuar dentro de los grandes lineamientos del pensamiento jurídico de la época.

Por considerarlo pertinente en relación con el tema que nos ocupa. Es decir, en cuanto a la pregunta de por qué un derecho operaba, en algunos aspectos, conforme a la posición moral de la época y por qué el resto del privado, argumentaba un positivo a ultranza, aunque no fuere cierto, vale la pena hacer la siguiente disquisición:

Sobre la posición de los tratadistas en cuanto a derecho y moral, y pese a la cultura jurídica que se impartía en las facultades de jurisprudencia, reseña López Medina ${ }^{14}$, con excelente claridad y síntesis:

“Todos nuestros doctrinantes clásicos implícitamente parecen adoptar el siguiente esquema que refuerza el componente liberal de la distinción entre derecho y moral: de un lado la distinción entre derecho y moral sirve para proteger la

12. Lina María Mápura Ramírez, "La cultura jurídica en Colombia: Un fenómeno que necesita Actualizarse", tesis de maestría en Maestría en Derecho, Universidad Nacional de Colombia, 2013, 76, http://www. bdigital.unal.edu.co/9592/1/06699350.2013.pdf (25 de marzo de 2016).

13. Mápura Ramírez, "La cultura jurídica en Colombia: un fenómeno que necesita Actualizarse”, 80.

14. Diego Eduardo López Medina y Duncan Kennedy, Teoría Impura del Derecho, la transformación de la cultura jurídica latinoamericana (Bogotá: Legis Editores S.A., 2004), 222-223. 
privado (libertades de religión y culto, por ejemplo) frente a la intromisión legislativa; de la misma manera, la separación entre derecho y moral funciona también con el propósito de impedir la juridificación de los deberes de caridad o solidaridad, que también debe permanecer en el ámbito de lo interno. Así, en Claro Solar, Vélez y Champeau y Uribe aparece la misma clasificación de los deberes jurídicos.

La presencia que tuvo la Iglesia Católica en las primeras décadas del siglo XX en la educación colombiana no se evidenció únicamente en los niveles básicos, sino que también afectó a la universidad, incluyendo a las facultades de derecho. En la Regeneración se impuso la homogeneización de todos los programas académicos en torno al currículo de la Universidad Nacional; es decir, los programas de las distintas universidades tenían que corresponderse con el de las facultades a cargo del gobierno nacional15. A ello se le añadió: "En todo establecimiento de instrucción, sea público o privado, que se incorpore en la Universidad Nacional, deberá darse enseñanza de religión católica, por textos aprobados por la autoridad eclesiástica, y bajo la inspección del párroco del respectivo lugar"16.

Hay dos aspectos en especial que caracterizan esos últimos años del siglo XIX y las primeras décadas del XX y que reflejan el peso de la religión en la academia. El primero, el control moral que se imponía en los distintos reglamentos por la Iglesia y, en segundo lugar, la permanencia de la cátedra de "Derecho canónico". Esta asignatura va a estar presente durante bastante tiempo y en varias universidades.

En igual sentido, llama la atención el hecho de que el derecho notarial no aparece reseñado en ningún currículo, lo que evidencia que pese a la reforma de 1852 o posiblemente a causa de ella, ya que no se exigió la profesionalización de los notarios, esta actividad mantuvo elementos patriarcales de sujeción inmediata al poder político en los nombramientos y permanencia en el cargo y la fuerza de la costumbre en las actividades mismas de los despachos notariales. Nótese, como ya se ha advertido en otros apartes, cómo la literatura jurídica al respecto solamente alude a los procedimientos notariales, sin que exista ninguna teorización al respecto y la escasa o nula vinculación de la formación académica de los abogados con el quehacer notarial. Como un ejemplo de los intereses académicos específicos de las facultades de derecho y la total inexistencia del derecho notarial en los pensum, se transcriben algunos planes de estudio de la época respectiva y se resaltan las materias asociadas con el derecho eclesiástico, como el indicado para tratar temas de familia.

15. Esta vinculación de todos los programas académicos al que se dictara en la Universidad Nacional se derogó hacia 1966, cuando se dio la libertad de que cada Universidad propusiera su propio plan de estudios. Catalina María Gutiérrez Giraldo y María Ximena Zárate Perdomo. Pensum histórico de la Facultad de Derecho de la Pontificia Universidad Javeriana. Tesis para optar por título de abogado. Pontificia Universidad Javeriana, 2001, 9.

16. Isabel Goyes Moreno, "La enseñanza del derecho en Colombia 1886- 1930". Tesis doctoral en Doctorado en Educación, Universidad de Nariño-RUDECOLOMBIA, 2008,147. 
Tabla 1. Materias

\begin{tabular}{|c|c|c|}
\hline \multicolumn{2}{|c|}{ Tipo de Deber } & Naturaleza Normativa \\
\hline \multicolumn{2}{|l|}{ Deberes con Dios } & Moral \\
\hline \multicolumn{2}{|l|}{ Deberes con uno mismo } & Moral \\
\hline \multirow{2}{*}{ Deberes con los demás } & Deberes de caridad & Moral \\
\hline & Deberes de justicia & Legal \\
\hline
\end{tabular}

\section{Plan de estudios Colegio Mayor Nuestra Señora del Rosario ${ }^{17}$}

Filosofía del derecho; Instituciones de derecho romano y su historia; Instituciones del derecho español y su historia; Instituciones de derecho público de los pueblos antiguos y modernos; Estudio especial de derecho público en Colombia; Derecho civil colombiano (dividido en dos cursos); Derecho mercantil comparado; Economía política, estadística y elementos de Hacienda Pública; Derecho internacional público y privado; Derecho penal y pruebas judiciales; Derecho procesal, civil y penal y práctica forense; y Derecho público eclesiástico ${ }^{\mathbf{1 8}}$.

\section{La Universidad Nacional}

En el caso de la Universidad Nacional, encontramos que en las tres primeras décadas del siglo XX y en los cinco cambios que hubo en el pensum de derecho, nunca se dejaron de ver asignaturas relacionadas con la Iglesia: Derecho público Eclesiástico (1892); Derecho Canónico (1894); Derecho Canónico (3 año) (1903); Derecho Canónico y procedimientos eclesiásticos (2 año) (1906); Derecho Canónico (2 año) (1927).

\section{El pensamiento neotomista en la educación de los abogados}

La filosofía del derecho, como elemento articulador y fundamento de los demás currículos, se mantuvo sin modificaciones importantes por mucho tiempo. En esta materia se enseñaba el iusnaturalismo de Tomás de Aquino y su pensamiento desarrollado por grandes pensadores colombianos, cuyo ejemplo más notable fue el Ms. Rafael María Carrasquilla. Este religioso y educador marcó el derrotero de la filosofía en universidades durante la época de la Hegemonía Conservadora e inclusive tiempo después. Rector del Colegio Mayor de Nuestra Señora del Rosario entre 1890 y 1930, año en el que fallece, convirtió al Colegio Mayor de Nuestra Señora del Rosario en un referente de lo que es la educación escolástica y

17. La Facultad de Derecho que funcionaba en el Colegio Mayor del Rosario pasó a manos de la Universidad Nacional hasta 1904, momento en el cual, bajo la dirección de Rafael María Carrasquilla, volvió al control del Colegio Mayor.

18. Fernando Mayorga García, El Estado y el Colegio del Rosario en el siglo XIX una historia de luces y sombras (Bogotá: Editorial Universidad del Rosario, 2010), 461. 
neotomista19, por lo que, inclusive, algunos historiadores afirman que "el Colegio del Rosario era un centro neotomista de gran importancia en Colombia"20. La renovación que Carrasquilla le dio a este pensamiento llegó a tal punto que el Rosario fue nombrado en diversas revistas internacionales, en reconocimiento de la apropiación que se hizo de esta reflexión, en tierras americanas ${ }^{\mathbf{2 1}}$, muy acorde con la línea doctrinal señalada por León XIII, desde Roma. Durante el rectorado de Carrasquilla en el Rosario se presentaron varias tesis de grado que tenían como eje central el pensamiento tomista y una crítica a las posturas positivistas, lo que indica como la ideología defendida por el rector afectaba directamente la producción académica de sus estudiantes ${ }^{22}$.

Acorde con este pensamiento desarrollado por Carrasquilla se encuentra que para el año de 1925 y gracias a la publicación del Catálogo de la Biblioteca del Colegio Mayor de Nuestra Señora del Rosario, los autores leídos y consultados para ese momento incluían a Agustín Manuel Alarcón, autor que hacia el siglo XVIII publica Philosophia thomistica o Tractatus de dialéctica seu lógica parva in Collegio Rosarii, además de varios jesuitas. De igual modo hay que aclarar que Carrasquilla, quien obtuvo el título de Doctor en Teología otorgado por el Papa León XIII era defensor entusiasta de la Encíclica Aeternis Patris del mismo Papa, en la que se invitaba al estudio de la doctrina tomista.

Así las cosas, no había una gran diferencia entre los programas de las universidades públicas y privadas en las primeras décadas del siglo $\mathrm{XX}$, ya que el control de la Iglesia Católica condujo a que el pensamiento filosófico, al menos, estuviera regido por las ideas de Santo Tomás. Quizá los únicos casos que resultan diferentes son la Universidad Externado de Colombia y la Universidad Libre de Colombia.

\section{El Externado de Colombia}

El plan de estudios de la primera de las universidades nombradas, para 1889, era así: Derecho Romano; español; Civil patrio; Internacional; Mercantil; Fiscal;

19. Dentro de las Constituciones del Colegio Mayor de Nuestra Señora del Rosario, publicadas por Rafael María Carrasquilla en 1893 se afirma “Todo colegio, amén del fin común de educar, tiene alguno especial que lo distingue de los otros establecimientos de especie. En el Colegio del Rosario, el objeto peculiar -claro lo dice el señor Torres- es enseñar a los seculares -a diferencia de los religiosos- la doctrina filosófica de Santo Tomás". Valderrama Andrade, Carlos. "El movimiento Neo tomista orientado por monseñor Rafael Maria Carrasquilla en el Colegio Mayor de Nuestra Señora del Rosario", Thesaurus, Tomo XL (número 2) 1985, 332.

20. El esbozo biográfico del doctor Rafael María Carrasquilla, de Luis María Mora. Valderrama Andrade, Carlos. "El movimiento Neo tomista orientado por Monseñor Rafael María Carrasquilla en el Colegio Mayor de Nuestra Señora del Rosario", 339.

21. En el año de 1910 en la Revue Noe-scholastique de Philosophie salió un artículo titulado El centro neotomista en Colombia. El movimiento neotomista orientado por monseñor Rafael María Carrasquilla en el Colegio Mayor de Nuestra Señora del Rosario. Carlos Valderrama Andrade, "El movimiento neotomista orientado por Monseñor Rafael María Carrasquilla en el Colegio Mayor de Nuestra Señora del Rosario", 338.

22. Es tal la influencia de Carrasquilla en sus estudiantes, que varias de estas tesis le son dedicadas a él. 
Penal y procesal y Ciencias Políticas; Ciencia constitucional; Ciencia administrativa; Economía política; Estadística; Legislación; Práctica Parlamentaria; Organización y Pruebas Judiciales. La clase de religión en esta universidad solo era obligatoria para los estudiantes, cuyos padres lo exigieran ${ }^{23}$.

\section{La Universidad Libre de Colombia}

El primer plan de estudios de la Universidad Libre, en 1923, junto con su nómina de profesores, fue el siguiente:

Antropología: Dr. Jorge Bejarano.

Biología: Dr. Francisco Arteaga.

Sociología: Dr. César Julio Rodríguez.

Demografía y estadística: Dr. Felipe S. Paz.

Economía política: Dr. Luis F. Rosales.

Ciencia constitucional: Dr. Antonio José Restrepo.

Legislación: Dr. Enrique Millán O.

Derecho internacional público: Dr. Dionisio Arango Vélez.

Derecho administrativo: Dr. Ramón Rosales.

Derecho Civil primero: Dr. Alberto Sicard.

Derecho Romano 1 año: Dr. Valentín Ossa.

Hacienda Pública y legislación fiscal: Dr. Pedro Blanco Soto.

Judicial primer año: Dr. Luis F Latorre.

Derecho Romano 1 año: Dr. Miguel Arteaga.

Derecho civil Segundo año: Dr. Juan Quintero.

Derecho mercantil: Dr. Juan Samper Sordo.

Derecho penal: Dr. Carlos Arango Vélez.

Procedimiento penal: Dr. Remigio González.

Judicial Segundo año: Isaías Castro Vélez.

Derecho Internacional privado: Dr. Antonio José Montoya.

Civil tercer año: Dr. Carmelo Arango.

Pruebas judiciales: Dr. Santiago Ospina.

Medicina legal: Dr. Pablo A. Llinás.

Código de minas y legislación sobre hidrocarburos: Dr. Fabio Hernández. 
Como se observa, la clase de derecho canónico o de algún asunto relativo a temas relacionados con la ideología católica imperante, de conformidad con el Concordato y el Estado colombiano, no aparecen en el currículo del Externado o de la Libre, sin descartar lo siguiente: es altamente probable que en la materia de derecho internacional privado, así como en derecho civil, en lo relativo al régimen de las personas en asuntos de matrimonio se tocara el tema de la obligatoriedad de las normas derivadas del Concilio de Trento, debido a la existencia de posibles conflictos de leyes, cuando se aplicara a un nacional colombiano o a un extranjero residente en Colombia, así como es posible que existieran consideraciones parecidas en la cátedra de derecho internacional público en lo relativo a tratados entre dos Estados soberanos como lo eran Colombia y el Vaticano, considerando la existencia del Concordato y los pactos adicionales suscritos.

Pese a que el derecho notarial cruza transversalmente todas las materias de derecho civil, tales como civil-personas, civil-obligaciones, civil-bienes, civilcontratos, derecho agrario, civil-sucesiones y lo relativo a los negocios inmobiliarios en que participa el Estado, no aparece ninguna asignatura específica, relacionada con este derecho. En igual sentido, se destaca que el estatuto notarial de la época ocupaba 90 artículos (Arts. 2546 a 2636 del C.C.) y lo referente a Instrumentos Públicos se extendía desde el artículo 2637 al 2682 del Código Civil, por lo que resulta, al menos, extraño el poco interés por estos asuntos. Por supuesto, la escogencia de las asignaturas también es un indicador de la coyuntura y las necesidades políticas y económicas del país. De ahí, que podamos concluir que el poco interés en la prevención de conflictos judiciales, el control elitista y político de la designación y la permanencia de los notarios, en sus cargos, consecuente con una estructura premoderna de la burocracia diera como resultado una escasa conciencia en formación ciudadana, relativa a la autonomía individual y la tolerancia, en asuntos patrimoniales, para ese período histórico.

En conclusión, en las primeras décadas del siglo XX, en las dos universidades confesionales (Nacional y Colegio Mayor del Rosario) y en las dos universidades seculares (Externado y Libre) consultadas, se observan planes de estudio muy similares, sin que existiera una verdadera educación laica, en las facultades de derecho, pese a la prudente distancia que guardan los doctrinantes de derecho privado en relación con el derecho natural o con las doctrinas de la Iglesia, sin perjuicio de lo que debía ocurrir en derecho de familia y de personas.

No sobra subrayar que algunos teóricos europeos del derecho privado, a principios del siglo XX, "proponen un giro muy radical en la forma de ver y analizar el derecho que luego y con algunos años de diferencia, una nueva generación de jurisconsultos locales también comenzó a importar al país. Estos trasplantes teóricos tenían como propósito redireccionar tanto el derecho privado como el público hacia una concepción, en general, más moderna, positivista, progresista, secular y liberal. El período de trasplante teórico local cubre, en líneas gruesas, 
entre los años de 1916 a 1940"24, con una clara influencia de León Duguit, Francois Gény, L. Josserand, G. Ripert y J. Bonnecase.

Como se ha venido destacando, el oficio de escribanos y notarios, durante el siglo XIX, se fundamentó más en el conocimiento práctico previo de tales servidores en esos despachos y no porque existiera la necesidad estatal o académica de preparar abogados o personas para que desempeñaran cabalmente, mediante formación ilustrada, estos oficios. Por supuesto, las cosas no cambiaron significativamente durante la primera mitad del siglo XX, aunque ya comienza a ser visible la educación formal de los notarios en Bogotá y capitales de departamento. Sin embargo, el estatuto notarial que seguía vigente era el de 1852, el cual, como se dijo, no exigía profesionalización del notario ni tales despachos estaban incorporados formalmente dentro de un criterio racional de burocracia.

Adicionalmente se debe tener en cuenta que solamente hasta la segunda mitad del siglo XX se comenzó a reglamentar y controlar la institución notarial, de manera permanente y a través de un organismo centralizado. La vigilancia notarial estaba atribuida a los jueces civiles del circuito en lo civil, conforme lo preceptuaba la ley 40 de 1932, excepción hecha del intento de nacionalizar tal servicio, durante la dictadura de Rojas Pinilla, mediante el decreto legislativo 1778 de 1954, norma que fue suspendida salvo en lo referente a que los notarios de capitales de departamento debían ser nombrados por el Presidente de la República y a que existiría un departamento de vigilancia notarial, dependiente del Ministerio de Justicia.

Ya hacia la década de 1930, finalizada la Hegemonía Conservadora e iniciada la República Liberal, la educación universitaria, específicamente la del derecho, presenta algunas modificaciones, incluyendo la diversificación de los textos y los contenidos de la enseñanza. Es de rescatar que se comienza a poner de presente el derecho a la cátedra libre por parte de los estudiantes y los profesores, al menos dentro de la Universidad Nacional. En el reglamento de 1939, se afirma que: "La facultad no aprueba ni desaprueba las opiniones emitidas en las tesis: tales opiniones deben considerarse propias de los autores"25. Inclusive, unos años antes, para el año de 1927 el reglamento de la Universidad Nacional si bien sigue imponiendo un comportamiento claro, por ejemplo, no asistir a clase bajo los efectos de la morfina, ya no rige su normativa de comportamiento con base en la moral católica.

En materia de asuntos jurídicos, debe mencionarse el fuerte ascendiente que, en su momento, tuvo Léon Duguit en la corriente liberal modernizadora del gobierno de Alfonso López Pumarejo. La posición de este gran jurista y pensador francés fue la de disminuir la distancia entre el derecho privado y el derecho público lo que teóricamente se tradujo en introducir la noción de la función social

24. López Medina y Kennedy, "Teoría Impura del Derecho, la transformación de la cultura jurídica latinoamericana", 235.

25 Universidad Nacional de Colombia. Facultad de Derecho y Ciencias Políticas: Reglamento (Bogotá: Imprenta Nacional, 1939), 48. 
de la propiedad privada en el derecho, a lo que se suma su teoría del servicio público, de gran influencia en el derecho administrativo colombiano. Este jurista afirmaba que el fin de cualquier derecho, radica en conservar la cohesión social y promover el bienestar de la comunidad ya que el derecho surge de la vida social y las relaciones sociales. Esta tesis se oponía a la concepción clásica del derecho natural, bien fuesen provenientes de la razón o de la revelación divina ${ }^{26}$, lo que representa otro paso hacia la laicidad del derecho y del Estado colombiano. A nivel anecdótico, debe comentarse, que Léon Duguit fue el único de los teóricos europeos que estuvo en el país: visitó la Universidad Nacional en 1921, donde dictó una conferencia; Darío Echandía reporta el evento, pero no se conocen detalles de la conferencia ni de su visita ${ }^{27}$.

Esta tendencia, en derecho público, no alcanza a opacar la posterior influencia de Kelsen en la educación de los abogados colombianos ni en la forma como se aplica el derecho en este país, ni tuvo impacto en el derecho notarial colombiano que ha seguido la línea del neoclasicismo kelseniano, aún hoy. Kelsen se introdujo en Colombia de la mano de dos libros de filosofía: Lógica, fenomenología y formalismo jurídico (1942) de Luis Eduardo Nieto Arteta y Ambiente axiológico de la Teoría Pura del Derecho (1947) de Rafael Carrillo. Este prestigioso teórico del derecho, sin proponérselo y en el contexto colombiano, aportó "una visión tranquilizadora de la cientificidad del derecho"28 ya que permitió alejar a jueces y abogados de las dificultades innovadoras de la crítica antiformalista de Gény ${ }^{29}$ y Duguit. En otros términos, el nuevo pensamiento le dio fundamento teórico suficiente a la validez del ordenamiento jurídico colombiano, pero no necesariamente legitimidad positivista, puesto que nuestra cultura jurídica y nuestro modo de vincular la ética con el derecho, seguía profundamente influenciado por las doctrinas católicas. Baste señalar que la justificación política de nuestro ordenamiento jurídico encontraba su fundamento en las normas constitucionales de la época, las que tenían un carácter claramente confesional y que la filosofía que se impartía en las facultades de derecho, era la neotomista, impartida bajo la, también, poderosa influencia en Colombia, de Ms. Rafael María Carrasquilla, para las respectivas justificaciones éticas.

\section{La educación de los abogados, en asuntos de personas y de familia}

La educación en las facultades de derecho, finalizando el periodo conocido como de "la Violencia", no varió sustancialmente. Sigue ausente el derecho notarial, salvo en materia de derecho de bienes y sigue teniendo mucha importancia para el estudio del derecho civil personas y de familia y sus instituciones, el derecho

26. Jaramillo Uribe, “Ensayos de historia social”, 257.

27. López Medina y Kennedy, "Teoría Impura del Derecho, la transformación de la cultura jurídica latinoamericana", 236.

28. López Medina y Kennedy, "Teoría Impura del Derecho, la transformación de la cultura jurídica latinoamericana", 357.

29. López Medina y Kennedy, "Teoría Impura del Derecho, la transformación de la cultura jurídica latinoamericana", 357. 
canónico, habida consideración que la presencia de la Iglesia en estos temas sigue siendo hegemónica, pese a los esfuerzos reformatorios que se intentaron en la República Liberal.

Debe anotarse, desde ahora, que el pensum de la Universidad Nacional de 1961 aún incluía dicha materia, la cual se veía en el quinto año. Ya para 1971 y los planes curriculares posteriores, 1972 y 1984 esta materia ya no aparece ${ }^{30}$. En comparación con el caso de la Universidad Nacional tenemos el caso de la Pontificia Universidad Javeriana, cuyo programa de Derecho se fundó hacia 1931 y en el cual la cátedra de derecho canónico estuvo siempre presente. En el mismo sentido, ocurrió en el Colegio Mayor de Nuestra Señora del Rosario.

Fecha de aparición de la materia: 1931.

Desapariciones: entre 1937-1938; entre 1970-1971; entre 1985-1993; entre 1994-2000.

Cronología:

Primer año: 1931-1936.

Segundo año: 1939-1969, 1993, 1994.

Cuarto año: 1972-198431.

\section{Universidad Nacional $1959^{32}$}

Primer año: Derecho civil primero; Derecho constitucional general; introducción al estudio del derecho; Derecho romano I; Derecho canónico; Derecho español e indiano; Economía general; Doctrinas sociales.

Segundo año: Derecho civil de bienes; Derecho constitucional colombiano; Derecho romano; Derecho internacional público y americano; Sociología general y americana; Medicina legal; Economía colombiana.

Tercer año: Derecho civil obligaciones; Derecho penal general; Derecho administrativo general; Derecho del trabajo I (individual); Legislación tributaria; Hacienda pública; Minas y petróleos; Seminario: Derecho internacional; Seminario: Derecho civil.

30. Carlos Villamil Ardila, Aproximación histórica a la Facultad de Derecho, Ciencias Políticas y Sociales de la Universidad Nacional de Colombia (Bogotá: Universidad Nacional de Colombia, 2001), 110, 128, 131 y 133.

31. Catalina María Gutiérrez Giraldo y María Ximena Zárate Perdomo, "Pensum histórico de la Facultad de Derecho de la Pontificia Universidad Javeriana”. Tesis de pregrado en Pontificia Universidad Javeriana, 2001, 95, https://nanopdf.com/download/pensum-historico-de-la-facultad-de-derecho-de-lapontificia_pdf (25 de marzo de 2016).

32. Villamil Ardila, "Aproximación histórica a la Facultad de Derecho, Ciencias Políticas y Sociales de la Universidad Nacional de Colombia”, 97. 
Cuarto año: Derecho civil contratos; Derecho procesal civil general; Derecho de familia; Derecho penal colombiano; Derecho procesal penal; Derecho del trabajo II (Colectivo); Derecho comercial general; Derecho administrativo especial; Seminario: Derecho comercial; Seminario: Derecho administrativo.

Quinto año: Derecho civil sucesiones; Derecho procesal civil especial; Derecho procesal penal especial; Derecho probatorio; Filosofía del derecho; Derecho procesal de trabajo; Derecho internacional privado; Derecho comercial Especial; Seminario: Legislación bancaria y de seguros; Seminario: Práctica procesal civil; Seminario: Práctica procesal penal; Seminario: Práctica procesal del trabajo; Ética profesional $^{33}$.

\section{La teoría Pura del derecho y el Derecho Notarial}

A fin de precisar la gestión concreta de los notarios respecto de su función como abogados al servicio de la sociedad, es primordial identificar su labor hermenéutica en el transcurso de los años, ya que pasó de simple instrumentadora hasta bien entrado el siglo XX a garantizadora, a partir de 1991.

No puede perderse de vista, entonces, que la interpretación de las normas como las decisiones cotidianas estuvieron caracterizadas por la costumbre en notarías. En otros términos, lo usual fue reproducir formatos de negocios jurídicos, a mano o a máquina de escribir, con muy poco rigor legal de parte de los amanuenses, dependientes del notario. En la medida que el ejercicio del derecho se fue profesionalizando y las exigencias por la seguridad jurídica fueron más complejas, también se sustituyeron las prácticas notariales, hacia una hermenéutica sustentada en la exégesis francesa, propia del neoclasicismo. En tal sentido, a partir de $1940^{34}$, esta forma de ver el derecho, encuentra su apoyo bajo el gran manto justificativo de la Teoría Pura del Derecho de Hans Kelsen, cuyo

33. Consejo académico de la Universidad Nacional, Acuerdo Número 20 de 1959, Acta número 12. 2.

34. "Estas tesis que se dicen extraídas del derecho positivo son presentadas, como hemos visto, en los tratados prekelsenianos más exegéticos tales como "El Estudio sobre el Derecho Civil Colombiano" de Fernando Vélez. Este tipo de positivismo ha estado ya presente, desde entonces hasta nuestros días, en la enseñanza diaria y el estudio de todas las áreas del derecho. Solo los más vanguardistas de los analistas locales (como Champeau, Uribe y Rodríguez Piñeres) estaban en posición de rechazar parcialmente la exégesis e implementar la metodología no positivista de la Begriffsjurisprudenz. Sin embargo, los lectores de estos libros de texto (profesores y estudiantes) por lo general desdeñaban los elementos constructivistas y conceptualistas en las teorías que estos jurisconsultos presentaban y simplemente asumían que los conceptos, principios y teorías así creadas eran emanaciones directas del derecho positivo vigente. ... El positivismo prekelseniano que se acaba de exponer constituye la teoría más común del derecho en nuestro medio. El positivismo prekelseniano sigue siendo la teoría jurídica subyacente e inconsciente que se prefiere localmente para la práctica jurídica...Su invisibilidad solo refuerza su poder: se trata todavía de la base más o menos incuestionable del derecho para los que no tienen el tiempo o la paciencia para embarcarse en el examen crítico de los supuestos recibidos. Su bajo perfil, su pretendida objetividad, su conexión con la práctica jurídica, su impaciencia frente a lo teórico o crítico, todo ello termina por asegurar su hegemonía”, López Medina y Kennedy, "Teoría Impura del Derecho, la transformación de la cultura jurídica latinoamericana". 
horizonte hermenéutico fue distinto ${ }^{35}$. La "exégesis kelseniana", como particular forma de interpretar el derecho fue muy visible, en nuestro país, hasta $1990 \mathrm{y}$ aún hoy, perdura como la técnica más sencilla y práctica de aplicación de normas jurídicas, en muchas instancias judiciales y administrativas, incluidas las notariales. Con todo, no sobra puntualizar que en la teoría jurídica hispanoamericana hubo algunas obras que tuvieron en cuenta las diversas tendencias alemanas y francesas, a lo que no fue totalmente ajeno el derecho notarial con la producción de alguna doctrina crítica y teorizante en Colombia ${ }^{36}$.

Esta preferencia interpretativa ha obedecido a varias razones. Éstas nos permitirán entender en forma más abarcadora cómo se han reconocido los derechos subjetivos individuales desde la perspectiva cultural laica o religiosa, tanto del ciudadano como del operador jurídico. La comprensión de estas relaciones nos permitirá esclarecer, también, la pregunta sobre si ellas han influido en el principio de la confianza pública notarial y, por tanto, si han contribuido a una independencia del derecho notarial respecto de otras ramas del derecho y a una cultura de formación ciudadana en tolerancia y de respeto por las opiniones contrarias, en espacios públicos.

La primera observación alude a que, pese a que el notario ha sido caracterizado como un particular que ejerce funciones públicas, mediante la figura administrativa de descentralización por colaboración, hace parte del aparato del Estado. Su legitimación funcional se deriva del ejercicio de una atribución exclusiva de éste. Por tanto, sus actividades también deben ser estudiadas desde el enfoque teórico de las organizaciones públicas, con las salvedades necesarias, en cuanto a sus particularidades. Al respecto, resultan muy pertinentes los análisis de Robert Merton en relación con la burocracia, a partir de las tesis de Max Weber. Afirma este conocido sociólogo que "el personal de la burocracia, cuando ésta debe privilegiar el conocimiento, la eficacia y la precisión en sus tareas, experimenta un desplazamiento de metas hacia los valores de lo instrumental como el objetivo a alcanzar". Señala Merton, que el ritualismo apegado rígidamente a los procedimientos formales obstaculiza la adaptación a los $\operatorname{cambios}^{37}$ y que "Los funcionarios se identifican

35. “... Kelsen reconoce el papel creador del derecho por parte de los jueces... en cuanto a la interpretación, distingue entre la interpretación auténtica, que realizan los órganos aplicadores y la interpretación del científico del derecho; la primera consiste en actos de voluntad que se realizan en cada momento de la aplicación del derecho, pues las normas son marcos abiertos a distintas posibilidades; esto es, el derecho, según Kelsen está parcialmente indeterminado hasta llegar al momento de la ejecución y no existen reglas del método jurídico que permitan conducir al intérprete a un único resultado (por eso, la seguridad jurídica, no puede ser más que relativa)", Manuel Atienza Rodríguez, El sentido del Derecho (Barcelona: Planeta S.A., 2010), 291.

36. Carlos Pinzón Urdaneta, Derecho notarial (Imprenta del Departamento, 1953); Germán Guzmán Campos, Orlando Fals Borda y Eduardo Umaña Luna, La violencia en Colombia (Ediciones Tercer Mundo, 1962); Francisco Martínez Segovia, Función notarial. Estado de la doctrina y ensayo conceptual (Buenos Aires: Ediciones Jurídicas Europa-América, 1961); Manuel Cubides Romero, Derecho Notarial Colombiano (Bogotá: Universidad Externado de Colombia, 1978); Gabriel Noguera Echeverri, Aspectos de la fe notarial (Bogotá: Pontificia Universidad Javeriana, 1973).

37. Gina Zabludovsky Kuper, Intelectuales y burocracia. Vigencia de Max Weber (México, D.F.: Coedición Anthropos y Fac. CC. Políticas y Sociales, UNAM, 2009), 45. 
sentimentalmente con su modo de vida y son portadores de "un orgullo de gremio" que los lleva a apegarse a las rutinas consagradas y resistirse a las novedades ${ }^{38}$. De manera muy similar, pero desde otro punto de vista, comenta Norberto Bobbio que cuando se define el derecho como un instrumento para la conservación de un determinado grupo social, el intérprete del derecho adopta una tarea de reconstrucción conceptual y sistemática más que de valoración de intereses. Tal tarea conduce a que, al momento de la aplicación, se privilegie el orden y la certeza en detrimento de la justicia sustancial. De otra parte, afirma Bobbio, si se considera al derecho como una ciencia formal, la tendencia al orden, la permanencia y la coherencia son los principales puntos de apoyo para la comprensión del fenómeno jurídico y, por ende, del positivismo jurídico ${ }^{39}$. Esta apretadísima imagen de los operadores jurídicos describe muy bien los imaginarios culturales que se tienen, así como las razones que motivan la conducta formalista de muchos notarios y dependientes de notarios, en estos espacios.

De acuerdo con el principio de legalidad del Estado Liberal clásico, el poder ejecutivo y, en este caso, la autoridad de los notarios está circunscrita a las autorizaciones que la ley les concede y nada más. Un servidor público no puede ir más allá de lo que la ley o el reglamento se lo permiten. El particular, a su vez, puede hacer libremente lo que su autonomía le permita mientras no transgreda la ley. Esta regla de oro del derecho constitucional ha prevalecido por muchos años y puede sintetizarse de la siguiente manera: a los servidores públicos de todo orden, todo lo que no está permitido está prohibido, mientras que a los particulares todo lo que no esté prohibido, está permitido. Este principio de legalidad es consecuencia, dentro de un esquema de Estado Liberal clásico, de la generalidad y abstracción de la ley; la generalización garantiza la imparcialidad y la abstracción, la certeza. Sin embargo, esta forma de concebir la actuación del Estado, solo puede conducir a la búsqueda de la voluntad del legislador (en sentido genérico), como único norte interpretativo sin que se pueda incorporar algún valor autónomo; es decir, la consecuencia que se deriva del principio de legalidad es un positivismo formal y acrítico en la actuación estatal, escudado en la ciencia pura del derecho ${ }^{40}$.

Desde otro punto de vista, debemos mencionar que el principio de la voluntad consensual, sustentado en la expresión "Los hombres nacen y permanecen libres $e$ iguales en derechos" 11 fue el gran paradigma de la política y del derecho, a partir de la Ilustración y de las revoluciones norteamericana y francesa. De acuerdo con este arquetipo de la Modernidad, "la historia del derecho tiene un sentido y dicho sentido nos conduce a un mundo emancipado donde el Hombre no carga otras cadenas que las que él mismo se fija"42. Tal concepción hizo crisis a partir de la segunda mitad del siglo XIX, al objetarse con vigor y con lucidez por diferentes teóricos

38. Zabludovsky Kuper, "Intelectuales y burocracia. Vigencia de Max Weber", 46.

39. Bobbio, El problema del Positivismo Jurídico (México, D.F.: Distribuciones Fontamara S.A), 39.

40. Gustavo Zagrebelsky, El derecho dúctil (Madrid: Trotta, 2011), 28-33.

41. Artículo 1o de la Declaración de los Derechos del Hombre y el Ciudadano de 1789.

42. Alain Supiot, Homo Juridicus: Ensayo sobre la función antropológica del Derecho (Buenos Aires: Siglo XXI Editores, 2007), 130. 
sociales la falacia de esta máxima, al descubrirse, en la inequidad de las relaciones jurídicas y económicas individuales, las sombras de este modo de pensar. A causa de esta contradicción, de manera paulatina y en la medida que evolucionó el Estado intervencionista, durante el siglo XX, se fue dando una creciente injerencia normativa en los negocios privados, pese al paréntesis desregulatorio del Estado neoliberal, a finales del siglo XX y principios del XXI, que aún subsiste en muchos sectores estatales como, por ejemplo, con el régimen de sociedades mercantiles.

En materia contractual o en relación con ciertos actos jurídicos de importancia para la sociedad y que se llevan a cabo en notarías, el Estado mismo ha impuesto una serie de contenidos heterogéneos, de cargas y de límites regulatorios, en ocasiones, bastante detallados, a los que hay que someterse. Esta hiper reglamentación refuerza el positivismo formal y acrítico en la actuación estatal, al que hacíamos alusión, líneas atrás. Muchos de estos negocios privados se formalizan en notarías y se relacionan con garantías financieras, limitaciones a la transferencia de inmuebles por estar destinados a planes sociales, urbanísticos o de obras públicas, control de planes masivos de vivienda, protección de inembargabilidad en patrimonios de familias, etc.

Los usos sociales en negociaciones de contratos inmobiliarios o de alguna significación económica, han conducido a que el postulado de experiencia mediante el cual "en otras épocas, era suficiente con la palabra" sea inviable y casi que mal visto en el terreno de la prueba de las obligaciones, entre particulares. Muchas personas optan por la seguridad jurídica documental y trasladan la prueba literal, al Estado, el que, mediante un tercero, designado por el mismo Estado, actúa como un testigo de excepción, en razón al papel que le han conferido los interesados. No obstante, -costumbre u obligación-, el concurrir a notarías tiene un alcance mucho más amplio que el exclusivamente probatorio. Aunque parezca contradictorio a simple vista, tal práctica se fundamenta en la buena fe de los particulares ${ }^{43}$, quienes confían en que el notario sea el garante formal de las obligaciones que -de confianza- han contraído cada uno de los comparecientes. Así las cosas, este principio termina siendo la otra cara de Jano de la seguridad jurídica. En palabras de Karl Larenz, al referirse al principio de la buena fe: "el ordenamiento jurídico protege la confianza suscitada por el comportamiento de otro y no tiene más remedio que protegerla porque ... poder confiar es condición fundamental para una pacífica vida colectiva y una conducta de cooperación entre los hombres $y$, por tanto, de paz jurídica"44.

43. “a) La buena fe es una causa o creación de especiales deberes de conducta exigibles en cada caso de acuerdo con la naturaleza de la relación jurídica y la finalidad perseguida por las partes a través de ella. b) La buena fe es una causa de limitación del ejercicio de un derecho subjetivo o de cualquier otro poder jurídico c) La buena fe se considera como una causa de exclusión de la culpabilidad en un acto formalmente lícito y, por consiguiente, como una causa de exoneración de la sanción o por lo menos de atenuación de la misma”. Sentencia T- 469 del 17 de julio de 1992. M.P. Alejandro Martínez Caballero.

44. Sentencia T-469 del 17 de julio de 1992. M.P. Alejandro Martínez Caballero. 
Desde el ángulo puramente doctrinal, son varios los acreditados autores que clasifican al derecho notarial como un derecho público adjetivo o, en otras palabras, como una especie del derecho procesal, ya que regula las ritualidades propias que debe contener un instrumento público o privado, para generar convicción jurídica ${ }^{45}$, sin que sea necesario desatar una litis contenciosa, mediante sentencia. Esta visión del derecho notarial conduce a concluir que en los actos notariales hay dos relaciones distintas, una de ellas subordinada a la otra: la relación sustancial que reconoce el derecho subjetivo en concreto y la relación formal que le confiere seguridad jurídica a la primera. Desafortunadamente, este punto de vista puede resultar bastante simplificador porque termina acomodándose a un pensamiento instrumentalista y exegético, propio del neoclasicismo, que no se articula totalmente con su verdadero significado garantista, como se explicará más adelante.

Por último, el control adicional de legalidad que sobre la tradición de la propiedad inmueble, hacen las oficinas de registro de instrumentos públicos, obliga a que los notarios opten por el obedecimiento escrupuloso del precepto notarial, ya que, muchas veces, por la vía del criterio de autoridad de la entidad de supervisión, los ciudadanos -y, de manera secundaria, los notarios- vía reclamos de los usuarios se exponen a devoluciones costosas y demoradas, a lo que se añade el agravante del tiempo, cuando se hace uso de recursos por la vía gubernativa. En consecuencia, la actividad minuciosamente reglada del notario, sujeta a normas reglamentarias de derecho público, lleva, a veces, a una excesiva instrumentalización de su actividad, reflejada en la literalidad de las formas en los documentos que autoriza, conforme a ciertas reglas jurídicas. En suma, los actos jurídicos de los particulares son una fuente fundamental de regulación de los derechos subjetivos que tan poco le gustaban a la Teoría Pura del Derecho, como se comentará más adelante. Ellos ocupan un gran espacio en cualquier sociedad organizada porque el ejercicio de los mismos son la derivación de la libertad de elección y, en muchos casos, de la libertad de conciencia.

La Escuela normativista de Viena, representada por Adolf Merkl y Hans Kelsen será la gran protagonista en la manera de entender el ordenamiento jurídico en la tradición del "Civil Law". Esta Escuela tendrá una gran ascendiente en la interpretación y aplicación de las normas, de parte de los tribunales y las instancias administrativas, durante gran parte del siglo XX y en lo que va corrido del siglo XXI, tanto en Europa continental como en América Latina ${ }^{46}$. Esta postura doctrinal tiene la influencia del neokantismo, según la cual toda ciencia debe tener pureza metódica y, por tanto, una teoría científica del derecho solamente puede centrarse en su objeto, que no es otro que las formas normativas, despojadas de elementos

45. Castán y Tobeñas, Gonnella, Saage, Otero y Valentín citados por Cubides Romero y Cubides Romero, "Derecho notarial colombiano", 107, 119.

46. A nivel doctrinal en Iberoamérica, la difusión de la obra de Kelsen se debe principalmente a Luis Recasens Siches, Luis Legaz Lacambra y Eduardo García Maynez. 
extrajurídicos, incluidos los valores ${ }^{47}$. Asimismo, en Europa, la Teoría Pura del Derecho será el final del camino en relación con los valores de la Modernidad, en materia de derecho; en ella, la pretensión de ser una ciencia especializada, con fundamento en la positivización de las normas y, por consiguiente, totalmente separadas de contenidos religiosos, anuncian la supremacía de la razón y del individualismo, así como la clara separación de lo privado y lo público, en materia de creencias íntimas. Asimismo, el énfasis de la teoría en el monopolio de la coacción legítima por parte del Estado, determinarán que éste será el único marco de referencia, imparcial y objetivo, de la regulación de las relaciones sociales en la comunidad ${ }^{48}$.

Para Kelsen, el concepto Estado de Derecho es una tautología puesto que su argumentación descansa sobre el principio de jerarquía de normas "...una norma sólo es válida, si ella satisface, por sus condiciones de emisión y/o en su contenido, las condiciones previstas por otras normas de nivel superior" 49 . En otros términos, el derecho y el Estado son dos fenómenos simultáneos, ligados indisoluble y recíprocamente, en el cual la coerción del Estado juega un rol definitivo ya que éste es el orden jurídico total. Consecuencia de lo anterior es que el componente fundamental de la Teoría Pura del Derecho se centra en que se enlaza una conducta, con su consecuencia objetiva contemplada en la norma, mediante una conexión llamada imputación en la que no caben los juicios de valor. "Esto lo expresa Kelsen cuando afirma que la teoría pura del derecho es ciencia del derecho y no política jurídica. Para él, los valores pertenecen a la política, que es el terreno de la ideología y de las aspiraciones irracionales de los hombres ${ }^{50}$. Aunque no parezca, a simple vista, este relativismo ético estuvo ligado a la defensa de la democracia, la tolerancia y la libertad y fue, en su momento, una forma de oponerse a las visiones unívocas de valores de los totalitarismos del siglo $\mathrm{XX}^{51}$, mediante los cuales la visión mesiánica y moral de una ideología o la razón de Estado, prevalecía sobre el criterio de igualdad legal o de la dignidad humana. En otros términos, el ejercicio de la autonomía privada en los actos jurídicos, al sustentarse en la generalidad de la ley, abstracta e impersonal, sin consideraciones éticas o políticas, preservaría el sistema liberal de la neutralidad del Estado frente al derecho a la libertad de elección y de conciencia.

Un aspecto particularmente sensible dentro de la Teoría Pura del Derecho es su posición en relación con los derechos subjetivos. La acepción generalizada de esta clase de derechos es entenderlos como la facultad o facultades que la norma jurídica concede a un sujeto de derecho para hacer algo permitido por

47. Gregorio Robles, "El Pensamiento Jurídico de Hans Kelsen: Una lectura crítica de la teoría Pura del Derecho”. En: Filosofía del Derecho, Andrés, Botero Bernal (coordinador) (Medellín: Universidad de Medellín, 2012), 232-233.

48. Jacques Chevalier, El Estado Posmoderno (Bogotá: Universidad Externado de Colombia, 2011), 173174.

49. Jacques Chevalier, El Estado de Derecho (Bogotá: Universidad Externado de Colombia, 2015), 54.

50. Robles, "El Pensamiento Jurídico de Hans Kelsen: Una lectura crítica de la Teoría Pura del Derecho".

51. Atienza, "El Sentido del Derecho", 291. 
el ordenamiento jurídico y su mejor ejemplo es el ejercicio de las prerrogativas jurídicas que confiere el derecho de propiedad. Para Kelsen, la norma es una regla establecida por el Estado en un momento determinado, y de ahí deriva su poder coactivo hacia el futuro, mientras que el derecho subjetivo se sustenta en una pretensión válida por sí misma, anterior a la ley misma. Esta idea típicamente iusnaturalista implica que los derechos subjetivos tienen una existencia autónoma al Ordenamiento Jurídico, sin que aparezca el elemento coacción estatal como esencial, lo que sí ocurre con las demás normas. En este orden de ideas, la construcción doctrinaria sobre derechos reales y personales, que son la especie del género -derechos patrimoniales subjetivos- descansa sobre este sistema. Desde la óptica de la teoría kelseniana, el derecho subjetivo es un oximorón porque el elemento coercitivo no encaja dentro de la lógica del ejercicio de una facultad, de una autorización o permiso. Añade, Kelsen, igualmente, que, dentro de la teoría pura del derecho, el concepto independiente y sustantivo es el "deber ser" expresado en la norma jurídica, por lo que el ejercicio de una facultad o permiso es simplemente reflejo de ese deber ser, queriendo significar con ello que si alguien tiene una facultad de hacer algo (derecho subjetivo) es porque se la ha otorgado previamente el derecho objetivo. En otros términos, la "lectura" del derecho subjetivo desde el lado de quien se beneficia de su cumplimiento no añade nada al contenido de las proposiciones jurídicas contempladas en un ordenamiento, porque su fundamento es una hipótesis conectada a un supuesto de hecho y a una sanción por medio del nexo deber ${ }^{52}$.

\section{El Neopositivismo de H.L. Hart y el derecho notarial}

Este filósofo escribe "El Concepto del Derecho" en 1961. Su objetivo fue formular una teoría descriptiva de esta rama del saber, moralmente neutral y como institución social y política controlada por reglas, en un Estado de derecho ${ }^{53}$, pero se aparta de la concepción normativista de Hans Kelsen, quien ya había hecho el recorrido de la leyenda en el mundo del derecho occidental, procurando salvar algunas objeciones de fondo a la misma. Señala este autor que la Teoría Pura del Derecho contempla el derecho desde el punto de vista del transgresor de la norma, sin tener en cuenta que son muchos los casos en que los preceptos son aceptados por sus destinatarios.

Según Hart, en un sistema jurídico pueden distinguirse dos tipos de normas: las primarias como aquellas que prescriben que los sujetos de derecho hagan $\mathrm{u}$ omitan ciertos actos, lo quieran o no; y las secundarias, que se subclasifican en la regla de reconocimiento, la que confronta a qué sistema jurídico pertenece la norma; las normas de cambio, que indican cómo se pueden modificar o crear las normas y

52. Robles, "El pensamiento jurídico de Hans Kelsen: Una lectura crítica de la Teoría Pura del Derecho", 274-275.

53. Gil Barrera, "El concepto de derecho y el post scriptum al concepto de derecho de H.L. A. Hart". En Filosofía del Derecho, Andrés Botero Bernal (coordinador) (Medellín: Universidad de Medellín, 2012), 436. 
quién puede hacerlo y las normas de adjudicación o de juicio que establecen quién debe decidir sobre la infracción de una norma y sus consecuencias. Estas normas secundarias confieren potestades públicas o privadas; públicas, como la facultad de dictar sentencias o promulgar leyes y privadas, como realizar contratos $\mathrm{u}$ otorgar testamentos ${ }^{54}$.

En cuanto a la naturaleza jurídica de las reglas secundarias, aplicables en su totalidad al derecho notarial, aunque las instituciones inglesas no tengan parecidos de familia con el derecho notarial latino, expresa Hart:

"Las reglas jurídicas que definen la manera de realizar contratos, celebrar matrimonios u otorgar testamentos válidos, no exigen que las personas actúen de modos determinados, lo quieran o no. Tales normas no imponen deberes $u$ obligaciones. En lugar de ello, acuerdan a los particulares, facilidades para llevar a cabo sus deseos, al otorgarles potestades para crear, mediante ciertos procedimientos específicos y bajo ciertas condiciones, estructuras de facultades y deberes dentro del cuadro coercitivo del derecho.

La potestad así conferida a los individuos para dar forma a sus relaciones jurídicas con los demás mediante contratos, testamentos, matrimonios, etc., es uno de los grandes aportes del derecho a la vida social; y es una característica que queda oscurecida si se representa a todo el derecho como una cuestión de órdenes respaldadas por amenazas. La radical diferencia de función entre las normas que acuerdan dichas potestades y una ley penal se refleja en muchos de nuestros modos corrientes de hablar acerca de las normas de aquella clase. Al otorgar nuestro testamento podemos "cumplir" o no con lo establecido en el artículo 9 de la Ley de Testamentos de 1837, en cuanto al número de testigos. Si no cumplimos, el documento no será un testamento válido que crea derechos y deberes; será un "acto nulo" sin "fuerza" o "efecto" jurídicos. Pero, aunque sea un acto nulo, nuestra falta de cumplimiento con la cláusula legal no es una "infracción" o una "violación" de ninguna obligación o deber, ni un "delito" ("offence"), y sería un factor de confusión concebirla en tales términos.

Si examinamos las diversas reglas jurídicas que confieren potestades a los particulares, veremos que ellas, a su vez, pueden agruparse en tipos diferenciables. Así, tras la potestad para otorgar testamentos o celebrar contratos hay reglas relativas a la capacidad o condición personal mínima (tal como ser mayor de edad y cuerdo) que deben tener aquellos que ejerciten dicha potestad. Otras reglas detallan la forma y manera en que la potestad ha de ser ejercida, y determinan si los testamentos o los contratos pueden ser hechos verbalmente o por escrito, y en este último caso, cómo han de ser realizados y autenticados. Otras reglas delimitan la variedad, o el plazo máximo o mínimo de duración, de las estructuras de derechos y deberes que los individuos pueden crear mediante tales actos jurídicos. Son ejemplos

54. Atienza, "El sentido del Derecho", 72. 
de tales reglas las normas de orden público relativas a los contratos, o las reglas contra accumulations en los testamentos o transacciones"55.

En cuanto a la forma de asumir el derecho notarial como práctica, Hart, al igual que Kelsen, sostiene la separación entre el derecho y la moral, pero precisa que se deben establecer unos mínimos de justicia, de manera racional, en toda organización social para que ésta sea viable (la vulnerabilidad humana, la igualdad aproximada de los hombres, el altruismo limitado, los recursos limitados o la comprensión y fuerza de voluntad limitados); pero estos mínimos, no tienen carácter universal e inmutable. Del mismo modo, una norma tiene carácter jurídico, no por razones morales, sino porque el propio ordenamiento le otorga validez jurídica ${ }^{56}$. No obstante, Kelsen no le da mayor importancia a los derechos subjetivos, lo que sí ocurre con Hart quien le da una gran importancia a la eficacia simbólica del derecho. Esta forma de concebir el derecho, será de gran utilidad para entender los mecanismos de la justicia preventiva, si consideramos el gran aumento de las regulaciones estatales, especialmente en lo relativo a derechos civiles de primera generación y la disminución del poder instrumental de las normas, a causa de las representaciones simbólicas de la eficacia del derecho, fenómeno bastante visible en notarías.

\section{Conclusión: La función interpretativa actual de los notarios}

A partir de la Constitución de 1991, la profesionalización de los notarios comenzó a tomarse en serio ya que, pese a que las funciones notariales empezaron a responder a las nuevas reconfiguraciones de una burocracia legal-racional, a partir de 1970, persistían algunos rasgos pre modernos, que solamente terminaron de superarse en este periodo. Un breve resumen de lo ocurrido, en cuanto a estabilidad del cargo, es la siguiente: aunque desde $1931^{57}$, la actividad notarial fue catalogada como servicio público y se les quitó a las asambleas departamentales, antes llamadas asambleas electorales, la facultad de intervenir en el nombramiento de notarios, función que detentaban desde 1873, este cargo siguió teniendo una significación de pago de favores políticos. En 1954, el nombramiento de notarios dependió del Presidente de la República y en 1959 se le entregó esa facultad, nuevamente a los gobernadores, de ternas enviadas por los Tribunales Superiores de Distrito Judicial.

Solamente hasta el año 2006, y luego de dos decisiones muy claras de la Corte Constitucional, los notarios fueron elegidos por concurso, de acuerdo con criterios ajenos al botín burocrático, propiedad de los partidos tradicionales y al pago de

55. Herbert Hart, El concepto de derecho (Buenos Aires, Argentina: Abeledo Perrot, 1963), 35.

56. Atienza, "El sentido del Derecho", 293.

57. Acto legislativo No. 1 de 1931, artículo 188 de la anterior Constitución. “Compete a la ley la creación y supresión de Círculos de notaría y de Registro y la organización y reglamentación del servicio público que prestan los notarios y registradores". 
favores políticos ${ }^{58}$. Luego de la Constitución de 1991, se han celebrado tres concursos, el primero de ellos con muchos tropiezos motivados por las maniobras de algunos de los notarios de la época, quienes se negaban a entregar sus despachos e hicieron hasta lo imposible para abortar el concurso, por el riesgo de quedar por fuera. El asunto tuvo tanta trascendencia en cuanto a la profesionalización de los notarios, que se renovó algo más de la mitad de la nómina de los notarios del país, luego de este primer concurso.

La selección de méritos, sin duda, transformó la actividad notarial mejorándola notablemente puesto que la actividad contó no solamente con una sana competencia, que permitió el ingreso o permanencia de los más capacitados sino que la estabilidad en el cargo logró un mejor servicio, la atención personal de profesionales del derecho en las funciones asignadas y una relación más directa con los objetivos y finalidades del Estado en materia de justicia preventiva, solución de conflictos ciudadanos de diversa índole y formación ciudadana.

58 “CARRERA NOTARIAL Y PRINCIPIO DE IGUALDAD-Implicaciones sobre concurso: La regulación afecta la carrera notarial, la cual, como ya se vio, es establecida por la propia Carta al ordenar que los cargos en propiedad de notarios sean provistos por concurso. En efecto, en reiteradas oportunidades esta Corporación ha manifestado que la carrera para el ejercicio de funciones públicas se fundamenta en tres principios interrelacionados: de un lado, la búsqueda de la eficiencia y eficacia en la función, por lo cual la administración debe seleccionar a la persona exclusivamente por su mérito y capacidad profesional. De otro lado, la protección de la igualdad de oportunidades, pues todos los ciudadanos tienen igual derecho a acceder al desempeño de cargos y funciones públicas. Finalmente, la protección de los derechos subjetivos de quien pertenece a la carrera, tales como el principio de estabilidad en el empleo, el sistema para el retiro de la carrera y los beneficios propios de la condición de escalafonado, pues las personas vinculadas a la carrera son titulares de unos derechos adquiridos, que deben ser protegidos y respetados por el Estado. Ahora bien, es claro que la regulación impugnada afecta estos principios. De un lado, la norma vulnera el principio de igualdad en el acceso a la función pública, puesto que sólo quienes ya son notarios pueden ingresar a la carrera notarial, cuando la Carta establece, conforme lo ha señalado con claridad esta Corporación, que los concursos para incorporarse a la carrera tienen que ser abiertos". Sentencia C-741 de 1998. Corte Constitucional, M.P. Alejandro Martínez Caballero.

59 “...En relación con la petición formulada por el actor y que el señor Procurador apoya para que adicionalmente se ordene la convocatoria, en un plazo perentorio del concurso de méritos que permita la provisión en propiedad de los cargos de notario por parte del Gobierno, la Corte estima necesario hacer las siguientes consideraciones. Es claro que en el presente caso la solicitud del actor y que apoya el señor Procurador no alude al restablecimiento de derechos subjetivos en concreto y por tanto a favor de personas determinadas -como sucede en los procesos de tutela-. Para la Corte es igualmente claro que en circunstancias de real excepción como la que se presenta en este caso, donde se está frente a una actuación del Legislador que se enmarca dentro de un incumplimiento reiterado de los mandatos superiores que han llevado incluso a la Corte a declarar la configuración de un estado de cosas inconstitucional, el análisis que debe hacerse y las consecuencias que dentro del marco de los objetivos del control abstracto de constitucionalidad cabe derivar, no excluyen la posibilidad de ordenar una determinada actuación en función del respeto y guarda integral de la supremacía de la Constitución Política. Por ello en armonía con anteriores pronunciamientos de esta Corporación además de declarar INEXEQUIBLE la expresión "164" contenida en el artículo 11 de la Ley 588 de 2000, a partir de la fecha de promulgación de la misma ley, la Corte ordenará como consecuencia que el Consejo Superior a que se refiere el artículo 164 del Decreto ley 960 de 1970, proceda a la realización de los concursos abiertos para la provisión en propiedad por parte del Gobierno del cargo de notario, en un término máximo de seis (6) meses contados a partir de la notificación de la presente sentencia, en cumplimiento del artículo 131 de la Constitución Política, y de conformidad con lo dispuesto en los artículos pertinentes de la Ley 588 de 2000 y demás normas concordantes" (Sentencia 421 de 2006, Corte Constitucional, M.P. Alvaro Tafur Galvis). 
Planteadas así las cosas -en el día a día-, a los operadores jurídicos, incluidos los notarios colombianos, se les generan dilemas tales como, si frente a determinada decisión que involucre garantizar el ejercicio de derechos civiles, sea mejor tomar partido por la posición liberal mediante la cual la libertad de creencia y de conciencia, y la protección de la vida, la libertad personal y la propiedad son el núcleo del derecho privado subjetivo ${ }^{60} \mathrm{y}$, por tanto, no deben "justificarse a partir de ninguna concepción particular de la vida buena" 61 o si, por el contrario, deba inclinarse por la postura republicana mediante la cual prevalecen los derechos de participación y comunicación política, que posibilitan la autodeterminación ciudadana ${ }^{62}$, enfoque que obliga a asumir una determinada conducta, en ocasiones, para fines que no se han escogido o no se comparten debido a finalidades asignadas por concepciones religiosas hegemónicas, o por nuestras identidades como miembros de una familia, un pueblo, una cultura o una tradición ${ }^{63}$.

La posición liberal se acerca bastante a la concepción mediante la cual la norma notarial, al estar desprovista del juicio sobre valores morales en su aplicación, de acuerdo con la interpretación kelseniana y tener una finalidad procedimental, por tanto, no debe "justificarse a partir de ninguna concepción particular de la vida buena". En tales circunstancias, la solución, cuando hay desacuerdo moral, pudiera llevarse a otros niveles de decisión como, por ejemplo, la negociación gubernamental en instancias reglamentarias o legales, sin intervención del operador jurídico o desplazando la discusión al terreno de los asuntos enteramente privados, para lo cual sería improcedente la mediación activa de este servidor público. Sin embargo, a esta solución, hay que añadirle un ingrediente que cambia radicalmente el sabor de la receta. Ocurre, más de una vez, que las disputas de procedimiento son, a menudo tan serias como el desacuerdo sobre el contenido, porque, en realidad, son una máscara que oculta una discusión moral de fondo que el Estado no ha podido resolver satisfactoriamente. Ejemplo muy sencillo de esta circunstancia ha sido el debate sobre el matrimonio igualitario y la definición de familia, contenida en el código civil colombiano.

Desde la perspectiva republicana, la decisión notarial ofrece también sus dificultades. En primer término, si se ha de tomar una decisión que posibilite "los derechos de participación y comunicación política y la autodeterminación ciudadana" debemos considerar qué tan bien informado está el notario sobre el problema moral que se le propone, como es su posición personal en términos de equidad o igualdad y qué tipo de argumentos está dispuesto a tomar en serio frente a la disyuntiva moral que se le plantea, aspectos que serán fundamentales si se ha de

60. Jürgen Habermas y John Rawls, Debate sobre el Liberalismo Político (Barcelona: Paidós, 1998), 66.

61. Michael Sandel, Filosofía Pública, ensayos sobre moral en política (Barcelona: Marbot Ediciones, 2007), 282.

62. Jürgen Habermas y John Rawls, “Debate sobre el Liberalismo Político”, 66.

63. Sandel, "Filosofía Pública, Ensayos sobre moral en política”, 284. 
tomar una decisión que eventualmente exija una interpretación del precepto aplicable. Desde el punto de vista del usuario, la perspectiva resulta problemática no solo porque los ciudadanos parecen encontrar formas válidas de vínculo jurídico que, en principio, pueden considerarse en conflicto con el ordenamiento jurídico, sino porque tales ideas, antes confinadas al ámbito privado, reclaman cada vez con más fuerza, su propio lugar en asuntos públicos y así lo exigen los ciudadanos.

Cualquiera que sea la opción que se tome, la liberal o la republicana, el notario se verá obligado a un juicio de valor, respecto del cual tendrá que tomar partido, si pretende llevar el asunto a buen término, en actitud conciliatoria, preservando la igualdad material de las partes y tratando de hacer justicia preventiva. Es decir, su papel trasciende la función puramente instrumental para convertirse en garante de los derechos civiles de los ciudadanos, dentro de los lineamientos que ha enriquecido la Corte Constitucional, en Colombia.

De estas certidumbres, surgen unos interrogantes:

¿Qué papel deben asumir los notarios, en el mundo de la autonomía privada, cuando el conflicto ético-religioso se hace presente? ¿Qué camino hermenéutico debe escoger y por qué?: ¿debe orientar sus decisiones, obligatoriamente, dentro del marco de una neutralidad liberal, propia de la concepción clásica del Estado de derecho o dirigirlas a una posición republicana, en clave determinista o comunitarista, sujeta al acatamiento de determinados valores superiores compartidos? o ¿debe encaminarse hacia la tolerancia de las posturas posmodernas, mediante la cual no es posible unir libertad y ley porque lo que debe reivindicarse como sujeto de libertad es al individuo concreto, liberado de experiencias morales abstractas?

En términos más precisos. Si los notarios son instrumentos de mediación entre la autonomía privada y el Estado ¿Debe prevalecer la tolerancia y la libertad de elección (en las notarías) cuando también están en juego diferentes concepciones republicanas de vida buena o posmodernas de corte estético-individualista, por respeto a la autonomía privada? ¿Los ciudadanos nos hemos apropiado realmente de la autonomía individual y de la libertad de conciencia, en las prácticas jurídicas notariales o sobresale la concepción neo-clasicista del Estado sobre los individuos?

Retomemos el ejemplo del matrimonio de parejas del mismo sexo. Hace un par de años, la Corte se inhibió de resolver de fondo afirmando que el Congreso era el legitimado para legislar sobre el punto y si, en el transcurso de un año, no se disponía al respecto, les correspondería a los notarios proceder a formalizar las solicitudes en tal sentido. Pasado el tiempo, y puesto que el Congreso no abordó el tema mediante una ley, les correspondió a los notarios acatar la decisión de la Corte. En su momento, intervino la Procuraduría señalando que, si algún notario casaba a una pareja del mismo sexo, sería investigado disciplinariamente. Los re- 
presentantes del gremio señalaron que debían obedecer a la Corte Constitucional, pero al no existir legalmente el matrimonio entre parejas del mismo sexo, tales uniones se llevarían a cabo en notarías, mediante un procedimiento denominado unión solemne de parejas del mismo sexo. Ante la insatisfacción de la solución, los defensores de estos grupos iniciaron las acciones constitucionales pertinentes y, por fin, en el año 2016, mediante la sentencia SU 214 de 2016, la Corte Constitucional autorizó los matrimonios de parejas del mismo sexo e hizo una serie de precisiones importantes sobre la función garantista de los notarios en cuanto a derechos humanos y el deber de obedecer los presupuestos valorativos concebidos por la misma Constitución.

La Corte Constitucional, en algunos de sus apartes expresó:

"En Colombia, los significados social y jurídico de la palabra "matrimonio" han evolucionado, de la mano de diversas tendencias, influencias, tensiones y oscilaciones. La evolución del matrimonio da cuenta de que su actual configuración responde a la existencia de complejas interacciones entre aspectos de carácter cultural, religioso, sociológico, económico, ideológico y lingüístico. Su comprensión desborda el ámbito de lo estrictamente jurídico, llegando inclusive a lo que el antropólogo alemán Arnold Van Gennep denominó el "escenario nupcial" o el "rito de pasaje", significando con ello la importancia que el simbolismo matrimonial tiene para los individuos, sus familias y la sociedad en general".

"Interpretar que las parejas del mismo sexo deben realizar un contrato solemne, que no configura un matrimonio civil conduce, entre otros, a los siguientes resultados: (i) no se constituye formalmente una familia; (ii) no surgen los deberes de fidelidad y mutuo socorro; (iii) los contratantes no modifican su estado civil; (iv) no se crea una sociedad conyugal; ( $v$ ) los contratantes no ingresan en el respectivo orden sucesoral; (vi) resulta imposible suscribir capitulaciones; (vii) no se tiene claridad sobre las causales de terminación del vínculo entre los contratantes; (viii) de llegar a establecer su residencia en otros países, las respectivas autoridades no les brindarían la protección legal que tienen los cónyuges a la unión solemne, ya que éstas no les reconocen los efectos que tienen en nuestro sistema jurídico; y (ix) en materia tributaria no se podrían invocar ciertos beneficios por tener cónyuge o compañero permanente. En conclusión, ningún contrato solemne innominado o atípico, celebrado entre parejas del mismo sexo, podría llegar a producir los mismos efectos personales y patrimoniales que un matrimonio civil".

"Los Jueces de la República, Notarios Públicos y Registradores del Estado Civil, al momento de adoptar sus respectivos actos judiciales, notariales o registrales, deben asegurar el ejercicio de los derechos fundamentales de los ciudadanos, acordándoles a todos, igual trato". 
La sentencia SU 696 de 2015, cuya magistrada ponente fue la doctora Gloria Stella Ortiz Delgado relativa a una acción de tutela presentada por los señores Antonio y Bassanio en representación de sus hijos Bartleby y Virginia contra la Registraduría Nacional del Estado Civil, el Ministerio de Relaciones Exteriores, las Notarías Segunda y 25 de Medellín, la Notaría Primera de Itagüí y la Notaría Segunda de Envigado, en relación con las obligaciones de las autoridades encargadas del registro civil en el caso de hijos o hijas de parejas del mismo sexo, destaca, igualmente, el papel de los notarios en el amparo de los derechos fundamentales de los ciudadanos, así:

“8. Desde sus inicios, este Tribunal ha abordado el análisis de tutelas dirigidas contra actuaciones realizadas por Notarios Públicos. Así, en la sentencia T-464 de 1995[147] el Tribunal conoció de una acción constitucional impetrada contra un notario que se abstuvo de resolver una petición ciudadana. En esa oportunidad, la Corte concedió el amparo al considerar que los notarios, como particulares que prestan un servicio público, están obligados por la Constitución a resolver de fondo las solicitudes que ante ellos eleva la ciudadanía.

Por otra parte, en la sentencia T-729 de 2011[148] la Corte conoció el caso de una tutela presentada contra un notario que se negó a corregir la fecha de nacimiento consignada en el registro civil de nacimiento. Es decir, las actuaciones notariales pueden ser sometidas al control de los jueces constitucionales, ya que las mismas tienen una relación estrecha con una serie de derechos fundamentales que se desprenden del reconocimiento de la existencia jurídica de las personas.

Este criterio fue ratificado por la sentencia T-551 de 2014[149], oportunidad en la cual la Corte conoció el caso de una tutela elevada contra la Notaría Primera de Bogotá por el padre de un menor de edad al que, después de nacer en Panamá, no le fue reconocida la nacionalidad colombiana. En este caso, el Notario accionado consideró que no era posible realizar tal reconocimiento debido a que en el certificado de nacimiento panameño el padre no realizó el reconocimiento de su hijo por lo que en el mismo solo estaba consignado el nombre de su madre. La Corporación en dicha oportunidad amparó los derechos del menor de edad y ordenó realizar la respectiva inscripción, argumentando principalmente que el derecho a tener un nombre, una nacionalidad y una filiación verdadera, así como el derecho al estado civil, hacen parte de los atributos de la personalidad y son reconocidos ampliamente por los tratados de derechos humanos ratificados por Colombia, así como por la Constitución y la ley. Por esta razón cualquier actuación de una autoridad pública, o de un particular que cumple funciones públicas, que los vulnere, debe ser corregida por los jueces constitucionales".

En el mundo de hoy, la crítica al positivismo formal ha tomado dos direcciones: el renacimiento del iusnaturalismo con una serie de variables laicas y religiosas y 
el realismo jurídico respecto del cual el contenido del derecho tiene que ver con el comportamiento de las personas disciplinados por las circunstancias y por los órganos de producción jurídica.

Respecto de la justificación y naturaleza del derecho, lo cierto es que un análisis riguroso de los fenómenos jurídicos y de una rama del derecho en particular, como es el derecho notarial exige partir de unos supuestos que no pueden soslayarse, por tratarse de asuntos que tocan con el comportamiento humano. En tales condiciones, la obediencia a los preceptos jurídicos, siempre estará condicionada por la presencia de valores culturales, intereses políticos, económicos y sociales prevalentes en un momento histórico determinado. Sobre este punto, con mucha precisión conceptual, señala Alain Supiot “...el hombre es un ser bidimensional, cuya vida social se desarrolla a la vez en el terreno del ser y en el del deber ser. El derecho no es revelado por Dios ni es descubierto por la ciencia, es una obra plenamente humana en la que participan quienes se dedican a estudiarlo y que no pueden interpretarlo sin tomar en cuenta los valores que transmite..."64.

Así las cosas, pese al poderoso influjo de la Teoría Pura del Derecho, elevada a la categoría de ciencia positiva, cuyo objeto es únicamente la norma jurídica, desligada de valores políticos o morales, no puede dejarse de lado el enorme peso cultural -positivo o negativo- que los significados éticos de origen religioso, han tenido en la aplicación del derecho, en nuestro país ${ }^{65}$. Estas señales externas están presentes en la intervención notarial, pero se requiere que se mire desde el enfoque de la teoría positiva, más general, de H.L.A. Hart a fin de entender más adecuadamente el punto. Dentro de este marco conceptual, las normas notariales

64. Supiot, "Homo Juridicus, Ensayo sobre la Función Antropológica del Derecho", 25-26.

65. "Seguidamente, en la sentencia C-224 de 1994 (la que configuró una fuente importante de las intervenciones que defienden la constitucionalidad de la norma que hoy se estudia), la Corte examinó la constitucionalidad del artículo 13 de la Ley 153 de 1887, el cual fue acusado por inconstitucional ya que hace referencia a la moral cristiana como cualidad de las costumbres que pretendan ser tomadas como fuente de derecho.

Pese a que podría argumentarse que en este pronunciamiento jurisprudencial la Corte no siguió estrictamente la línea que desarrolla la laicidad del Estado, lo cierto es que en esa oportunidad la Sala estableció que la única manera en que la expresión "moral cristiana" resultaba acorde con la Constitución, era entendiendo dicha expresión como referente a una "moral social" o "moral general", y así lo hizo explícito en dicha sentencia en su parte resolutiva. En atención a esto, en la C-224/94, se argumentó: "...la referencia hecha en el artículo 13 [de la Ley 153 de 1887], a la moral cristiana, no implica, como pudiera pensarse, una exigencia de carácter dogmático que suponga un privilegio para esa moral frente a otras. Significa, más bien, la referencia a uno de los elementos constitutivos de la costumbre, la "opinio juris", según la cual la costumbre, para que sea jurídica, debe generar en la comunidad que la observa, la convicción de obligatoriedad". 
son consideradas como reglas secundarias ${ }^{66}$ de cambio $^{67}$ sobre la base de la regla de reconocimiento ${ }^{68}$ con un impacto muy valioso ya que ha servido "no tanto para una reconstrucción del positivismo sino para una crítica de la ingenuidad lingüística del clasicismo;... la discusión hartiana sobre la "textura abierta del derecho" y la "regla del reconocimiento" se situó como la contribución más pertinente a las necesidades de transformación cultural del derecho local"69.

Ahora, la labor de los notarios en la aplicación de las normas sustantivas no se agota en el reconocimiento formal de una autonomía privada, merecedora de tutela legal, sino que incluye operaciones más complejas, tal como acaba de destacarse.

Al seguir la línea de pensamiento de la interpretación jurídica de Giovanni Tarello, pero partiendo de la visión del positivismo de H.L.A. Hart, podemos indicar que el reconocimiento de derechos subjetivos, en sede notarial, se cumple así: a) en primer término, el notario debe confirmar si el acto jurídico sobre el cual se solicita su intervención le corresponde una norma aplicable al derecho subjetivo concreto que se reconoce; b) asimismo, debe interpretar armónicamente la norma aplicable con contenidos indefinidos por la misma ley, con referencia al lenguaje ordinario de los contratos solemnes o de los actos jurídicos unilaterales que requieren solemnidad o son reconocidos ante notario; c) debe resolver las posibles antinomias, entre el lenguaje ordinario y los modos de concebir el derecho subjetivo que se garantiza, así como en relación con las ideologías hegemónicas relativas a su coherencia; d) debe integrar el derecho subjetivo que se reconoce con nuevas normas reguladoras y debe armonizar y buscar la integración con el derecho reglamentario del caso específico ${ }^{70}$, no sin olvidar, de manera terminante y sin asomo de duda, que "...Con miras a diferenciar la función jurisdiccional de la fedataria asignada a los notarios (la Corte Constitucional) ha aplicado criterios

66. “Las reglas primarias prescriben acciones u omisiones y esta regulación existe con independencia a la voluntad de los individuos... Las secundarias, en cambio, dependen de las primeras y su sentido puede ser el de conceder potestades públicas o privadas para el cambio, extinción o limitación de las reglas primarias" Gil Barrera, "El concepto de derecho y el post scriptum al concepto de derecho de H.L. A. Hart", 448.

67. “Son reglas que consisten en la concesión de potestades, públicas o privadas, para la creación, alteración o derogación de los contenidos de las normas primarias. Entre ellas están las que señalan la manera de realizar contratos, celebrar matrimonios u otorgar testamentos válidos" Gil Barrera, "El concepto de derecho y el post scriptum al concepto de derecho de H.L. A. Hart", 448.

68. "La regla de reconocimiento es una regla social que existe como una cuestión de hecho, es decir, como práctica o uso coincidente de tribunales, legisladores, funcionarios o personas particulares, cuando cada una de ellas verifican la validez de una norma por referencia a lo que ella expresa como criterio de identificación o pertenencia de estas normas a un ordenamiento jurídico". Gil Barrera, "El concepto de derecho y el post scriptum al concepto de derecho de H.L. A. Hart", 448; Jose Luis Aramburo Restrepo, Manual de Derecho Notarial: Funciones y responsabilidades (Bogotá: Legis Editores S.A., 1999), 48.

69. López Medina y Kennedy, "Teoría Impura del Derecho, la transformación de la cultura jurídica latinoamericana", 441.

70. G. Tarello, La interpretación de la Ley (Lima: Palestra Editores, 2013), 54. 
como: (i) la potestad decisoria y de adjudicación de derechos, propia de los jueces, no así de los notarios; (ii) el carácter contencioso, o de jurisdicción voluntaria, de la materia que origina la actuación; (iii) y la naturaleza coercitiva del procedimiento judicial, a diferencia del notarial regido por la autonomía de la voluntad"71.

Esta forma de aplicación del derecho en sede notarial, es la puerta de entrada a líneas hermenéuticas diferentes a la concepción mecánica y literal que prevaleció por mucho tiempo, bajo el ropaje "pop" de la teoría pura del derecho, según la conocida expresión del tratadista López Medina, en su obra "La Teoría Impura del Derecho ${ }^{72 "}$.

Estas formas de razonamiento, además, se imponen debido a la creciente constitucionalización del derecho privado y la actual visibilidad política y jurídica sobre protección de los derechos civiles de carácter individual. El espacio privado ha dejado de ser el límite de lo político y ha terminado convertido en espacio público, en razón a los debates que se plantean en cuanto a libertad de elección en derechos fundamentales y las decisiones políticas que se deben tomar ${ }^{73}$. Este nuevo panorama conduce a que, hoy, la legitimidad que se invoca de los actos notariales también tienda a flexibilizarse, para alejarse de la simple validez formal de la norma, como criterio de legitimidad. Los particulares y el Estado mismo se ven obligados a superar la legitimidad explícita de la ley por una legitimidad intrínseca; porque actualmente es necesario demostrar la pertinencia ciudadana del acto y la calidad del método escogido, a causa de la "racionalización" del mercado y del cuestionamiento del postulado de superioridad del Estado, luego de la crisis del Estado providencia, a partir de $1970^{74}$.

Por lo anterior, resulta oportuno recordar la siguiente interrogación del Maestro Mario Fernández Herrera: “ ¿El dador de fe notarial moderno, específicamente el notario como "jurista del contrato", se debe quedar aplicando la ley textualmente tal como sale del órgano legislativo? ¿no será que el texto de la norma debe superar su plano semántico para pasar al plano que resulta de la lectura de la realidad fenomenológica que el notario tiene al frente, esto es a un plano complejo y compuesto de circunstancias, necesidades, finalidades, unas del Estado y otras de los sujetos disponentes, valores axiológicos y multitud de factores que rodean la situación prácticajurídica-social del acto que se documenta?"75

71 Corte Constitucional Sentencia C-863 de 2012 del 25 de octubre 2012. M.P. Luis Ernesto Vargas Silva.

72. López Medina y Kennedy, "Teoría Impura del Derecho, la transformación de la cultura jurídica latinoamericana", 397.

73. Boaventura de Sousa Santos, Si Dios fuese un activista de los Derechos Humanos (Madrid: Trotta S.A. 2014), 76.

74. Chevalier, "El Estado Posmoderno", 125-126.

75. Ocaris Úsuga Varela, Estatuto del notariado colombiano, actualizado, concordado y comentado con doctrina y jurisprudencia (Bogotá: Ediciones Doctrina y Ley Ltda., 2016), 14. 
Desde este enfoque, la tarea final del notario termina siendo una especie de interpretación oficial revestida de una particular autoridad, conferida por el saber del notario. Simplemente se trata de no perder de vista que la significación que el notario le da a la relación jurídica que formaliza, le imprime a ésta, fuerza ejecutoria y vinculante entre las partes interesadas, en procura de la seguridad jurídica ${ }^{76}$. En tal sentido, cuando el notario confiere autenticidad a los actos y negocios jurídicos contenidos en los documentos que se le presentan, así como cuando aconseja y asesora en los contratos y actos civiles, protege y garantiza el derecho a la autodeterminación individual, a la inclusión social, al reconocimiento de la personalidad legal y a la nacionalidad ${ }^{77}$. Y su papel no puede ser el instrumental de hace muchos años atrás ni el refugio en teorías científicas y positivas, sin duda, plausibles, pero que conforme al desarrollo de la teoría jurídica han resultado insuficientes para dar solución a los problemas que suscita la autodeterminación privada, en el territorio de las creencias íntimas y los actos jurídicos.

En conclusión, la ubicación de las reglas notariales, con total independencia de su poder coactivo conducen a destacar que las mismas no son procesales o adjetivas, sino que, por el contrario, tienen una finalidad sustancial, más allá de la concreción de un derecho reconocido en otra norma: simbólica, legitimadora y preventiva ${ }^{78}$. Su finalidad simbólica se traduce en que las formalidades notariales se conciben como la exteriorización del consentimiento, bajo diversos efectos, según sea el caso; asimismo, su simbolismo se expresa como un mecanismo eficaz de la buena fe, de respeto y cumplimiento del acto jurídico celebrado al que se le aplica en toda la amplitud de su significado, la expresión de Niklas Luhmann refiriéndose al derecho como el subsistema social especializado en "estabilizar las expectativas de comportamiento"79. En cuanto a su finalidad legitimadora, el asunto puede mirarse desde varios puntos de vista: en muchos casos; habilitando los efectos de cada momento del iter contractual como ocurre con las promesas de negocio que se reconocen ante notario y la escritura pública que concreta la promesa como acto solemne esencial para la transferencia de inmuebles; en segundo lugar, en relación con la ineficacia general, de los actos jurídicos; la ausencia de las formas notariales puede conducir a la inexistencia, la nulidad absoluta o la inoponibilidad a terceros del acto respectivo, y constituyen una prueba, sin contestación, del efecto jurídico vinculado. De acuerdo con este papel central en el ejercicio de los derechos fundamentales y pese a la ambivalencia lingüística de la expresión "reglas secundarias" referidas a los derechos subjetivos, según la clasificación de H.L.A. Hart, es fácil comprender cuál debe ser el camino hermenéutico que hoy le corresponde al notario, en su quehacer diario.

\footnotetext{
76. Cubides Romero, "Derecho Notarial Colombiano", 141.

77. www.uinl.org (25 de marzo de 2016).

78. Aramburo Restrepo, "Manual de Derecho Notarial Funciones y Responsabilidades", 50.

79. Aramburo Restrepo, "Manual de Derecho Notarial Funciones y Responsabilidades", 136.
} 


\section{REFERENCIAS BIBLIOGRÁFICAS}

Aramburo Restrepo, José Luis, Manual de derecho notarial funciones y responsabilidades. Bogotá: Legis Editores S.A, 1999.

Atienza, Manuel. El sentido del Derecho. Barcelona: Planeta S.A., 2010.

Beltrán, William Mauricio, Del monopolio católico a la explosión pentecostal, pluralización religiosa, secularización y cambio social en Colombia. Bogotá: Universidad Nacional de Colombia, Facultad de Ciencias Humanas, Centro de Estudios Sociales CES, 2013.

Bobbio, Norberto El problema del positivismo jurídico. México, D.F.: Distribuciones Fontamara S.A., 1991.

Burns, Kathryn, "Dentro de la ciudad letrada: la producción de la escritura pública en el Perú colonial", Revista Histórica, Vol. 29, Núm. 1 (2005): 43-68, http://revistas.pucp.edu.pe/index.php/historica/article/ view/29/35.

Chevalier, Jacques, El Estado posmoderno. Bogotá: Universidad Externado de Colombia, 2011.

Chevalier, Jacques, El Estado de Derecho. Bogotá: Universidad Externado de Colombia, 2015.

Cubides Romero, Manuel. Derecho notarial colombiano. Bogotá: Universidad Externado de Colombia, 1978.

Duarte Salazar, J. La institución del notariado en Colombia. Bogotá: Universidad Nacional. 1944.

Gaitán Bohorquez, Julio, Huestes de Estado, la formación universitaria de los juristas en los comienzos del Estado colombiano. Bogotá: Centro Editorial Universidad del Rosario, 2002.

Gil Barrera, R. "El concepto de derecho y el post scriptum al concepto de derecho de H.L. A. Hart". En Filosofía del Derecho, Andrés Botero Bernal (coordinador). Medellín: Universidad de Medellín, 2012.

Goyes Moreno, Isabel, "La enseñanza del derecho en Colombia 1886-1930". Tesis doctoral en Doctorado en Educación, Universidad de Nariño-RUDECOLOMBIA, 2008.

Goyes Moreno, Isabel. La enseñanza colonial del derecho en la vida Independiente, http://ceilat.udenar.edu.co/ wp-content/uploads/2011/03/La-Ense\%C3\%B1anza-Colonial-del-Derecho-en-la-Vida-Independiente.pdf

Gutiérrez Giraldo, Catalina María y Zárate Perdomo, María Ximena, "Pensum histórico de la facultad de derecho de la Pontificia Universidad Javeriana". Tesis de pregrado en Pontificia Universidad Javeriana, 2001, https:// nanopdf.com/download/pensum-historico-de-la-facultad-de-derecho-de-la-pontificia_pdf

Habermas, Jurgen y Rawls, John, Debate sobre el liberalismo político. Barcelona: Paidós, 1998.

Hart, H. L. El concepto de derecho. Buenos Aires, Argentina: Abeledo Perrot, 1963.

Herzog, Tamar, Mediación, archivos y ejercicio. Frankfurt: Vittorio Klostermann Frankfurt am Main, 1996.

Jaramillo Uribe, J. Ensayos de historia social. México, D.F.: CESO, Ediciones Uniandes, ICANH, Alfaomega Colombiana S.A., 2001.

LeGrand, Catherine y Corso, Adriana Mercedes, "Los archivos notariales como fuente histórica: Una visión desde la Zona Bananera del Magdalena". Anuario Colombiano de Historia Social y de la Cultura, No. 30 (2003):159-208, http://www.bdigital.unal.edu.co/14282/1/3-8166-PB.pdf

López Medina, Diego E., y Kennedy, Duncan, Teoría Impura del Derecho, la transformación de la cultura jurídica latinoamericana. Bogotá: Legis Editores S.A., 2004. 
Mápura Ramírez, Lina María. “La cultura jurídica en Colombia: un fenómeno que necesita actualizarse”, tesis de maestría en Maestría en Derecho, Universidad Nacional de Colombia, 2013, 76, http://www.bdigital. unal.edu.co/9592/1/06699350.2013.pdf

Mijares Ramírez, Ivonne, Escribanos y escrituras públicas en el siglo XVI, el caso de la Ciudad de México. México D.F.: Universidad Nacional Autónoma de México, 1997.

Robles, Gregorio, "El pensamiento jurídico de Hans Kelsen: Una lectura crítica de la Teoría Pura del Derecho". En: Filosofía del Derecho, A. Botero Bernal (coordinador). Medellín: Universidad de Medellín, 2012, 237.

Palacios, Marco y Safford, Frank. Historia de Colombia, país fragmentado, sociedad dividida. Bogotá: Ediciones Uniandes, 2002.

Sandel, Michael. Filosofía Pública, Ensayos sobre Moral en Política. Barcelona: Marbot Ediciones, 2007.

De Sousa Santos, Boaventura, Si Dios fuese un activista de los Derechos Humanos. Madrid: Trotta S. A. 2014.

Savater, Fernando, El valor de elegir. Barcelona: Ariel, 2003.

Supiot, Alain. Homo Juridicus, ensayo sobre la función antropológica del Derecho. Buenos Aires: Siglo XXI Editores, 2007.

Tarello, Giovanni, La Interpretación de la Ley. Lima: Palestra Editores, 2013.

Umaña Luna, E., http://biblioteca.clacso.edu.ar/ar/libros/colombia/ces/jurisprudencia.pdf. Obtenido de http://biblioteca.clacso.edu.ar/ar/libros/colombia/ces/jurisprudencia.pdf (15 de septiembre de 2015).

Universidad Nacional de Colombia, http://www.archivo.bogota.unal.edu.co/page/historia.php (15 de septiembre de 2015).

Universidad Nacional de Colombia. Facultad de Derecho y Ciencias Políticas. Facultad de derecho y Ciencias Políticas: reglamento. Bogotá: Imprenta Nacional, 1939.

Uribe Ángel, Jorge Tomás, Historia de la enseñanza en el Colegio Mayor del Rosario 1653-1767. Bogotá: Centro Editorial Rosarista, 2003.

Úsuga Varela, Ocaris, Estatuto del notariado colombiano. Actualizado, concordado y comentado con doctrina y jurisprudencia. Bogotá: Ediciones Doctrina y Ley Ltda., 2016.

Villamil Ardila, Carlos, Aproximación histórica a la Facultad de Derecho, Ciencias Política y Sociales de la Universidad Nacional de Colombia. Bogotá: Universidad Nacional de Colombia, 2001.

Weber, Max, Sociología de la Religión. México, D.F.: Ediciones Coyoacán, 1997.

Zabludovsky Kuper, Gina, Intelectuales y burocracia. Vigencia de Max Weber, México, D.F.: Coedición Anthropos y Fac. CC. Políticas y Sociales, UNAM, 2009.

Zagrebelsky, Gustavo. El derecho dúctil. Madrid: Trotta, 2011. 